\title{
Breathing life into consumer rights: smartphone tools facilitating the "right to know" on substances of very high concern in REACH articles
}

\author{
Julian Schenten ${ }^{1}$, Mattheus Brenig ${ }^{2^{*}} \mathbb{D}$, Martin Führ ${ }^{1}$ and Kilian Bizer²
}

\begin{abstract}
Background: The EU chemicals regulation "Registration, Evaluation, Authorisation and Restriction of Chemicals" (REACH) aims to reduce the usage of substances of very high concern (SVHCs) by firms. Therefore, a consumer rightto-know about SVHCs in articles is intended to create market-based incentives. However, awareness of the right-toknow among EU citizens is low. Moreover, the response window of 45 days afforded to suppliers impedes immediate, informed decisions by consumers. Consequently, despite being in effect for more than 10 years, only few consumer send requests. Civil society actors have developed smartphone applications reducing information search costs, allowing users to send right-to-know requests upon scanning an article's barcode. Answers are stored in a database and made available to the public immediately. This paper assesses to which extent smartphone tools contribute to an increased use of the right-to-know by undertaking a case study of the application "ToxFox" by the German nonprofit organisation Bund für Umwelt und Naturschutz Deutschland (BUND).

Results: An analysis of the data from the BUND database for the period 2016 to 2018 reveals that about 20 thousand users have sent almost 49 thousand requests. This has led to more than 9 thousand database entries, including 189 articles which contain SVHCs above the legal threshold. The data also indicate that receiving information on requested articles encourages further use of the application. Many suppliers accept the application and pro-actively provide information on articles without SVHCS above the threshold. However, most consumers use the application only for a short time, and suppliers are struggling to reply to right-to-know requests.
\end{abstract}

Conclusion: Evaluating the results, the study identifies options to enhance the application's design in terms of user motivation and legal certainty, and to enhance the framework governing "barcode" assignments to articles with a view to better contributing to transparency. As for policy implications, a lack of consumer requests can in part be traced back to design flaws of the right-to-know and a lack of implementation and enforcement of REACH. In addition, suppliers have to increase their supply chain communication efforts to make sure they are in a position to properly answer consumer requests. We recommend several policy options addressing these and additional aspects, thus contributing to the legislative review of Art. 33 REACH.

Keywords: REACH Regulation, SVHCs, Substances in articles, Transparency instruments, Right to know, Mobile applications, Consumer behaviour, Supply chain communication, Regulatory impact assessment

\footnotetext{
*Correspondence: mattheus.brenig@wiwi.uni-goettingen.de

${ }^{2}$ Chair of Economic Policy and SME Research, University of Göttingen,

Platz der Göttinger Sieben 3, 37073 Göttingen, Germany

Full list of author information is available at the end of the article
}

\section{Introduction}

International law and policies call for transparency and a high level of protection concerning consumer articles with problematic substances, i.e. chemicals with intrinsic

\section{Springer Open}

(c) The Author(s) 2020. This article is licensed under a Creative Commons Attribution 4.0 International License, which permits use, sharing, adaptation, distribution and reproduction in any medium or format, as long as you give appropriate credit to the original author(s) and the source, provide a link to the Creative Commons licence, and indicate if changes were made. The images or other third party material in this article are included in the article's Creative Commons licence, unless indicated otherwise in a credit line to the material. If material is not included in the article's Creative Commons licence and your intended use is not permitted by statutory regulation or exceeds the permitted use, you will need to obtain permission directly from the copyright holder. To view a copy of this licence, visit http://creativeco mmons.org/licenses/by/4.0/. 
properties that may cause damage to human health and/ or the environment. For example, Art. 5(8) of the Aarhus Convention obliges party states to "develop mechanisms with a view to ensuring that sufficient article information is made available to the public in a manner which enables consumers to make informed environmental choices" [1]. A similar notion can be found in the 2015 UN Resolution "2030 Agenda for Sustainable Development", Sustainable Development Goal 12 "Ensure sustainable consumption and production patterns".

Transparency is not only considered a desirable objective in itself, but is also increasingly used as a regulatory instrument [2]. After direct regulation and economic instruments, transparency has been described as the "third wave" in toxic substance control, receiving political and scholarly attention in particular after considerable reductions of chemicals listed on the United States Toxic Release Inventory [3-7]. The premise of regulatory transparency is that it corrects for informational asymmetries between firms and the public and creates market-based incentives for firms, through consumer or public pressure, to change their behaviour according to a regulatory goal. These incentives result not only from actual changes of consumer demand, but also from firms' expectations thereof or perceived reputational threats posed by consumers or relevant advocacy groups [8-10]. However, as recent reviews of the literature show, information disclosure policies are often ill-designed and therefore fail to elicit the intended behavioural responses of consumers and firms $[2,8]$. For example, a prerequisite is that the disclosed information enables the public to easily discriminate between firms and articles based on certain criteria-in this case, the use of problematic substances [5]. Moreover, consumers are more likely to use information that they can easily access and take into account at the moment of decision-making $[8,11]$.

Although public disclosure is also an integral part of the European chemicals regulation $\mathrm{REACH}^{1}$, the provisions do not meet the aforementioned conditions and are therefore unlikely to create market-based incentives for firms to substitute problematic substances. In accordance with Recital $117 \mathrm{REACH}$, which states that "EU citizens should have access to information about chemicals to which they may be exposed in order to allow them to make informed decisions about their use of chemicals" (see also Art. 118, 119 REACH), most information collected under REACH is publicly available through the website of the European Chemicals Agency (ECHA). For

\footnotetext{
${ }^{1}$ Regulation (EC) No 1907/2006 of the European Parliament and of the Council, OJ 2006 L 396/1. REACH concerns the registration, evaluation, authorisation and restriction of chemicals and established the European Chemicals Agency.
}

example, the agency provides brief profiles of substances which contain information on hazard classification and labelling and how consumers and workers may be exposed. ${ }^{2}$ Profiles contain very high level information on the types of articles (e.g. plastic articles) substances are potentially used in, but no information about which firms actually use a substance in a specific product. Hence, consumers can at best use the information to decide whether to buy a certain type of article or not, but they cannot use the information to discriminate between different articles of the same type.

Although REACH does not disclose firm or article specific information, Art. 33(2) REACH gives consumers a right-to-know about so-called substances of very high concern (SVHCs) in certain articles upon request. More specifically, Art. 33(2) REACH stipulates that on request by a consumer, any supplier of an article containing a SVHC in a concentration above $0.1 \mathrm{wt} \%$ shall provide the consumer with sufficient information, to allow safe use of the article. This information must include, as a minimum, the name of the SVHC and must be provided, free of charge, within 45 days of receipt of the request. ${ }^{3}$ SVHCs are determined by competent $\mathrm{REACH}$ authorities in any EU Member State or by ECHA on behalf of the European Commission; the respective procedures are laid down in Art. 59(4) REACH. The first SVHCs were identified in late October 2008; until July 2020209 SVHCs have been added to the list. ${ }^{4}$ In the words of the European Commission, the right-to-know was included so "[c]onsumers can play an active role in the process [i.e. encourage companies to look for safer alternatives] by taking an interest in the safety of the products they buy" ${ }^{5}$. However, in comparison to e.g. information on product labels, consumers have to invest a relatively large amount of time and effort in exercising Art. 33(2) REACH: they need to research article and contact data, send a request to the firm and wait up to 45 days for a response. Indeed, existing information indicates that consumers have sparsely used their right-to-know. In the 2012 regulatory review of REACH, industry representatives reported that consumers made "limited use" [12] of the instrument. ${ }^{6}$

\footnotetext{
2 See https://echa.europa.eu/information-on-chemicals/.

3 The definition of "article" is quite broad and basically applies to all articles other than substances or mixtures (Art. 3(3) REACH). The "supplier of an article" is any producer or importer of an article, distributor or other actor in the supply chain placing an article on the market (see Art. 3(33) $\mathrm{REACH}$ ). Hence, consumers can e.g. address a request to the brand that manufactures and sells the article as well as retailers who only sell the article.

4 See https://echa.europa.eu/de/candidate-list-table.

5 http://ec.europa.eu/environment/chemicals/reach/right_en.htm.

${ }^{6}$ At the time of writing, there was no robust and comparative data or research on consumer use of Art. 33(2) REACH available.
} 
To address some of the limitations of Art. 33(2) $\mathrm{REACH}$ within the existing regulatory framework, European NGOs and public authorities have developed smartphone applications that help consumers submit right-to-know requests and collect firms' responses in a database to make them available to the public. Using the smartphone camera, the applications read an article's barcode (translating the Global Trade Item Number, GTIN) and allow users to access article information on SVHCs if available. Similar to product labels, users can easily access the information at the moment of decisionmaking and discriminate between articles, based on a simple binary categorisation (article does or does not contain SVHCs above $0.1 \mathrm{wt} \%$ ). Thereby, the applications essentially reduce waiting time from the legal time limit of 45 days to a few seconds. If the SVHC status of an article is not known to the application, users can send automatically generated Art. 33(2) REACH requests to firms. Information provided by firms in response is stored in a database and then immediately made available to other users. The applications thus lower information search costs for users, especially once the SVHC status of an article is known.

The main purpose of this paper is to provide a conceptual and empirical assessment of the relevance of the applications for facilitating the "right to know" on SVHCs in articles and thus fostering market-based incentives. In doing so, we focus on the smartphone application "ToxFox" by the German NGO "Friends of the Earth Germany" (BUND), which is one of originally only three existing tools of this kind and which has the largest user base [13]. In the following section, we give an overview of the existing tools and shortly explain their main features. We also discuss limitations of GTIN-based applications. Since the applications are based on Art. 33(2), all limitations associated with the legal provision also extend to the applications. We therefore explain the limitations of Art. 33(2) in its current implementation and related to its enforcement by authorities. In the 'Methods' section we shortly present the methods used in our empirical analysis. We analyse the application in its "initial stage" of database build-up. In the 'Results' section, we descriptively analyse data from BUND's database to assess the impact of the application in terms of the quantity of Art. 33(2) requests compared to the time period, before the right-to-know was added to ToxFox. The analysis also includes a regression analysis of the BUND data to make initial inferences regarding factors driving user behaviour. In the last section, we summarise the identified motivational, legal and technical barriers to an increased relevance of the application for market-based incentives. We then conclude with recommendations addressing governance issues and smartphone applications in the context of Art. $33 \mathrm{REACH}$ and suggest potential directions for future research.

Our paper contributes to the delayed legislative review of Art. 33(2) $\mathrm{REACH}^{7}$ which will gain momentum with the launch of the European Commission's "Chemicals strategy for sustainability (toxic-free EU environment)" expected in the third quarter of 2020 as one result of the European Green Deal [14]. Besides, the paper is one of the first to consider market-based incentives to reduce SVHCs under REACH $[15,16]$ and the first to analyse the right-to-know in this context. Moreover, BUND's data set provides us with the unique opportunity to observe and analyse individual consumer request behaviour over time.

\section{Background}

\section{Overview of consumer tools and approaches}

NGOs and public authorities have developed several tools to reduce the information search costs for consumers making right-to-know requests. Two approaches have been adopted: (1) help consumers file a request and (2) collect suppliers' responses in a database to make them available to other consumers and the public. As for the first approach, many actors offer(ed) sample letters in which consumers insert article details and personal contact data that can then be sent via mail or email. ${ }^{9}$ In 2012, the German Environment Agency (UBA) and the NGO "Friends of the Earth Germany" (BUND) released an online inquiry tool. Here, consumers had to fill in only the name of the article as well as its GTIN. The tool automatically sent the request to the owner of the GTIN. ${ }^{10}$ The next development step in this approach was introduced in 2017, when UBA launched the smartphone application "Scan4Chem". ${ }^{11}$ Consumers using this application first generated their personal profile by providing contact data. Subsequently, they could send right-toknow requests by scanning the barcode attached to an article. With this tool, sending requests from the point of sale became more convenient. However, the initial version of Scan4Chem and the other online inquiry tools did not help overcome the central limitation of Art. 33(2) $\mathrm{REACH}$, i.e. the response time frame of 45 days and lack of a public database with information on SVHCs in articles. Three other smartphone apps combine the approach of Scan4Chem with a database which stores suppliers'

\footnotetext{
${ }^{7}$ Refer to Art. 138 REACH for more details.

${ }^{8}$ https://bit.ly/39Ly24G

9 https://goo.gl/HBmP8b, https://goo.gl/LRwWVY.

${ }^{10}$ See https://goo.gl/HTqxDa. Owners of GTINS are listed in the database GEPIR (Global Electronic Party Information Registry) of GS1.

${ }^{11}$ https://goo.gl/7GDKEd.
} 
responses: (1) The app “Tjek Kemien” was launched in 2014 by the Danish Environmental Protection Agency and the NGO "Danish Consumer Council" (Forbrugerrådet Tænk); ${ }^{12}$ (2) The right-to-know was added to the scope of "ToxFox" in 2016 (see below), (3) UBA, BUND, the Danish Environmental Protection Agency and the Danish Consumer Council collaborated with additional agencies, NGOs and research organisations in the "LIFE AskREACH" project ${ }^{13}$ to develop an application similar to "Tjek Kemien" and "ToxFox", which was launched in 2019 in several European countries ${ }^{14}$ under different names. ${ }^{15}$

The possibility to send Art. 33(2) requests via the BUND application ToxFox was first introduced on 20 October 2016. However, ToxFox was officially launched in 2013. Until its update in October 2016, ToxFox users could only retrieve information on (potentially) endocrine disrupting chemicals (EDCs) contained in cosmetic products. ${ }^{16}$ Therefore, when interpreting the results of our empirical analysis, it should be taken into account that the application already had active users when the possibility to make SVHC requests was introduced. All previous functionalities for EDCs in cosmetic products are still available. Unfortunately, we have no data on the use of the EDC function for the time period covered by the data set used in our empirical analysis. Hence, we cannot compare the use of the EDC versus the SVHC function.

Regarding the SVHC function, after scanning the barcode of an article, the application shows its name and picture. If SVHC information for a requested article is available, the application lists the name of the substance(s) or informs the user that the article does not include SVHCs (above the legal threshold) according to the supplier. If the requested data is unavailable, users can send an automated request with a single click. Users can view their requests and monitor whether firms answer within the 45 day deadline set by REACH. Users who have not received an answer within the deadline can tick a "notify the supplier" box to resend the request. The section "Article search and history" lists previous articles looked at by the user in a certain period

\footnotetext{
12 http://tjekkemien.dk.

13 Cf. on the implementation project "LIFE AskREACH", funded within the framework of the LIFE Regulation (LIFE16 GIE/DE/000738) www.askreach. eu.

${ }^{14}$ https://www.askreach.eu/app-launches-across-europe/

${ }^{15}$ In Germany the application is called Scan4Chem and by its launch replaced the original Scan4Chem.

${ }^{16}$ In comparison to SVHCs articles, informing consumers about EDC in cosmetic products has the distinct advantage that, according to Art. 19(1) (g) Regulation (EC) $1223 / 2009$, the packaging those products has to be labelled with a list of ingredients.
}

and allows the search of articles using a text entry box. Hence, users do not need physical access to an article at home or in retail to send requests. ${ }^{17}$ BUND not only provides the smartphone application for consumers, but also a browser-based front end for article suppliers. ${ }^{18}$ Instead of responding to REACH requests via email, suppliers can answer pending requests via the front end. They can also pro-actively provide data for articles which have no pending requests. Entries may even refer to entire GTIN ranges. ${ }^{19}$ Moreover, registered suppliers receive email reminders every six months when the candidate list is updated. Once information on an article is entered, it is communicated automatically to users with pending requests. If suppliers do not use the front-end but respond directly to the email request, both BUND and the user will receive the email response and BUND will manually add adequate SVHC information to the database.

\section{Adequacy of GTIN-based applications as a communication tool for Art. 33(2)}

GTINs are an imperfect tool for identifying individual articles. First, suppliers sometimes assign the same GTIN to whole groups of articles, e.g. as in the case of fast changing collections [18]. Second and more importantly, specimens of the same article may originate from different production batches. For each batch, there can be different actors and process steps in the supply chain. This, in turn, may result in differing chemical compositions of articles, which may or may not trigger the Art. 33 REACH information obligations. However, the "GTIN Management Standard" states that only changes to the article formulation that affect the legally-required declarable information on the packaging of an article require a new GTIN. ${ }^{20}$ According to feedback from industry representatives during a workshop on the application, it is therefore not common practice to assign an individual GTIN to each production batch. ${ }^{21}$ Linking communication via the application to additional article identifiers (e.g. batch number) could thus constitute a possible solution.

Moreover, barcode owners, to whom requests are addressed, may be located outside the geographic

\footnotetext{
17 This function coincides with the observation that the point of decision increasingly deviates from the point of sale [17]. In addition, users can access background information on SVHCs, REACH and the societal relevance of the right-to-know.

18 toxcheck.info

19 Most barcodes are linked to a GTIN, assigned by the organisation GS1. Assessing their GTIN, the ToxFox identifies articles.

20 https://www.gs1.org/1/gtinrules/en/

21 https://goo.gl/fktTqV.
} 
jurisdiction of $\mathrm{REACH}$, i.e. outside the European Economic Area (EEA) and, hence, lack incentives to provide the requested data. Due to the high share of imported articles on the EU market, this is highly relevant. According to Eurostat, in 2015, about $56 \%$ of articles sold within the EU market have been imported into the EU-28 from third countries. A high share of these articles are assumed "articles" in terms of REACH [19]. ${ }^{22}$

Furthermore, there are some (alleged) legal uncertainties with respect to the role of BUND in the communication between consumers and firms. First, the BUND sends requests on behalf of consumers. [20] argues that recipients of requests sent via the application are not provided with an actual "procuration" and, thus, could suspend the request until such a document is received. One simple solution would be to add a tick box to the tool, allowing consumers to explicitly declare that they confer a mandate to BUND. This procuration could be attached to requests automatically. Alternatively, BUND could link every request on behalf of a consumer with a "twin-request" in their own right. All sorts of end-users of articles, including legal persons such as NGOs, are, as shown by the legal arguments in the next section, entitled to send requests under Art. 33(2).

\section{Limitations of Art. 33(2)}

\section{Design flaws in the REACH regulation and alleged legal uncertainties}

The legal framework creates some uncertainties and obstacles to the optimal use of applications. These barriers affect consumers either directly, or indirectly through firms.

The information right is not particularly consumerfriendly. If firms take full advantage of the legal time limit of 45 days, consumers may be discouraged from sending requests. Besides, according to Art. 33(2), firms are not obliged to answer if the requested article does not contain SVHCs above the legal threshold. This leads to uncertainties as to the conclusion that can be drawn from the absence of a response, as firms may or may not comply with their information obligations.

There are also a number of alleged legal uncertainties for firms. First, for firms to be able to inform consumers, information on substances needs to be communicated in the article supply chains. In this respect, REACH complements the "right to know" with a similar obligation stipulated by Art. 33(1): Within the professional supply chain,

\footnotetext{
${ }^{22}$ Another factor is related to the Global Electronic Party Information Registry (GEPIR) of GS1. Firms usually add contact details of employees in charge of commerce or logistics to GEPIR. Therefore, requests may ultimately not be forwarded to employees that are familiar with consumer rights under REACH.
}

suppliers of articles that contain SVHCs above $0.1 \mathrm{wt} \%$ have to actively provide the recipient of the article "with sufficient information, available to the supplier, to allow safe use of the article including, as a minimum, the name of that substance". In the REACH architecture, the processes steered by Art. 33(1) shall thus build the knowledge base necessary for a proper working of Art. 33(2). However, according to ECHA, "[t]here are clear indications that the information on substances is not adequately communicated in the article supply chains" [21, 22]. Hence, firms often do not know the SVHC contents of their articles [23]. The lack of supply chain communication affects brands' and retailers' ability to answer consumer requests. This raises the question of who is responsible if brands or retailers do not receive (any) SVHC information from their suppliers. Art. 33(1) does not oblige the recipients explicitly to actively request this information or to investigate this issue, in case no or only doubtful information was provided by their suppliers. However, article recipients such as brands and retailers remain fully responsible for the legal conformity of the articles they place on the market. Art. $33 \mathrm{REACH}$ thus strongly encourages suppliers of articles to build up organisational capacities which allow them to determine whether their articles or components thereof contain SVHCs above $0.1 \mathrm{wt} \%$. In fact, keeping the legal principle of proportionality in mind, the European Court of Justice (CJEU) ruled that this requirement "which is minimal in nature, cannot be regarded as being an excessive burden". ${ }^{23}$ A strategy of relying on supplier compliance would thus put professional recipients at risk [24]. This interpretation is in line with the explicit duties laid down in Art. 36 REACH which does not only contain the "obligation to keep information", as indicated by the title of the provision; rather, as a logical first step each "distributor shall assemble $[\ldots]$ all the information he requires to carry out his duties under this Regulation". The provision thus formulates the general "duty to organise" which is ultimately embedded in the principle of self-responsibility of commercial actors as laid down in Sentence 1 of Art. 1(3) REACH. Thus, REACH actors have to actively organise the information, communication and cooperation (IC\&C) processes in the supply chain on which the functioning of the various REACH mechanisms is based upon.

Second, Art. 33 REACH does not specify whether the $0.1 \mathrm{wt} \%$ value in case of articles that are complex objects (e.g. car, mobile phone, shoe) refers to the whole article or to each article it is composed of. Member states had enforced differing interpretations of the provision [25]

\footnotetext{
${ }^{23}$ CJEU, Case 106/14, $\$ 80$
} 
until the CJEU decided in favour of the "once an article always an article" approach: ${ }^{24}$ The 0.1 wt\% threshold applies to articles which were joined or assembled together to form a more complex object [26]. It also applies to the complex object itself if, e.g., this complex object is an assembly of two articles merged with adhesives that contain SVHCs above the threshold [26]. In addition, the packaging used for transport and presentation of an article is considered a separate article under $\mathrm{REACH}$ and is therefore separately subject to all article related provisions.

Third, as for the temporal scope of Art. 33(2), authorities most likely will not enforce information requests addressed at articles that have been placed on the market before REACH entered into force on 1st June 2007. For articles placed on the market thereafter, actors in the supply chains should have developed communication systems to ensure the flow of SVHC information. At least for articles placed on the market after 28th October 2008, when ECHA first published the candidate list, suppliers are obliged to communicate information on candidate list substances pursuant to Art. $33 \mathrm{REACH}$. More precisely, the communication duties are determined by the candidate list in effect at the time of request and not at market placement. Hence, as the list evolves, so do the communication duties of article suppliers. Contrary interpretations by authorities are not grounded in the legal text.

Fourth, Art.33(2) REACH does not give clear instructions on the kind of information that needs to be provided to a consumer upon a right-to-know request. However, for suppliers to ensure compliance, the response must, as a minimum (1) refer to the individual article in question, i.e. taking into account the specific production batch, (2) refer to SVHCs according to REACH, (3) declare the names of all SVHCs above $0.1 \mathrm{wt} \%$ contained in the complex article or its components which remain articles (and/or in the packaging), and (4) refer to the candidate list status as of the date of the request.

Fifth, Art. 33(2) confers the right-to-know to consumers. However, REACH does not provide an explicit definition of "consumer". The question thus arises whether in addition to natural persons (i.e. "private" consumers), legal persons (e.g. NGOs) are also entitled. In this respect, one may refer, on the one hand, to the communication requirement under Art. 33(1) directed towards the "recipient of an article" which, according to Art. 3(35), refers to "an industrial or professional user, or a distributor, being supplied with an article but does not include consumers." The definition, however, has to be understood in a way that it covers those actors who use the article in their professional domain similar to how a "downstream user" uses a substance or a mixture, e.g. during a production process. This understanding, on the other hand, does not mean that a company may not be in the position of a consumer in the sense of Art. 33(2), e.g. for their office supplies. The same holds true for other organisations, such as public authorities, schools, universities as well as NGOs purchasing articles used similarly for non-commercial (private) use. Consequently, all sorts of end-users of articles are entitled to file requests under Art. 33(2). Only industrial or professional actors using the article as an input stream within their production process as such or distributors in the supply chain are excluded, and so are persons who make a request without purchasing purpose, like scientists who want to make a study on SVHC requests [18].

\section{Quantity and quality of suppliers' answers}

Findings from Art. 33(2) compliance projects run by law enforcement, indicate that many firms do not reply to requests even if requested articles contain SVHCs above the legal threshold. Moreover, these projects showed that firms falsely state that their articles do not contain SVHCs in relevant quantities, as confirmed by chemical testing. In a pilot project of 15 Member States on the harmonised enforcement of substances in articles, 682 articles were inspected [23]. ${ }^{25}$ Out of these, 55 articles contained SVHCs above $0.1 \mathrm{wt} \%$. For these $55 \mathrm{arti}$ cles, the information obligation was fulfilled in 24 cases and not fulfilled in 31 cases (56\%). With regard to firms, 43 firms were obliged to answer, of which 21 companies complied with this obligation and 22 companies (51\%) did not. The lack of compliance indicates a lack of proper enforcement of the provision.

However, it is not possible to draw general conclusions on the situation of articles on the EU markets from these figures, as the pilot project focused on high risk articles or materials and targeted only a few SVHCs. Market surveillance for several reasons (including challenges of chemical analysis) usually focuses on a small fraction of SVHCs.

\section{Methods}

For our empirical analysis we use data from the proprietary database toxcheck.info of the BUND. Our main data set is built around the mail processor logs of the BUND database, where each entry refers to an email that was sent either by a user to a firm, i.e. a SVHC request,

\footnotetext{
${ }^{24}$ CJEU, Case 106/14 FCD and FMB v Ministre de l'Écologie, du Développement durable et de l'Énergie (2015), \$50.
}

\footnotetext{
${ }^{25}$ One goal of such projects is the harmonisation of the varying inspection strategies in member states [27-31].
} 


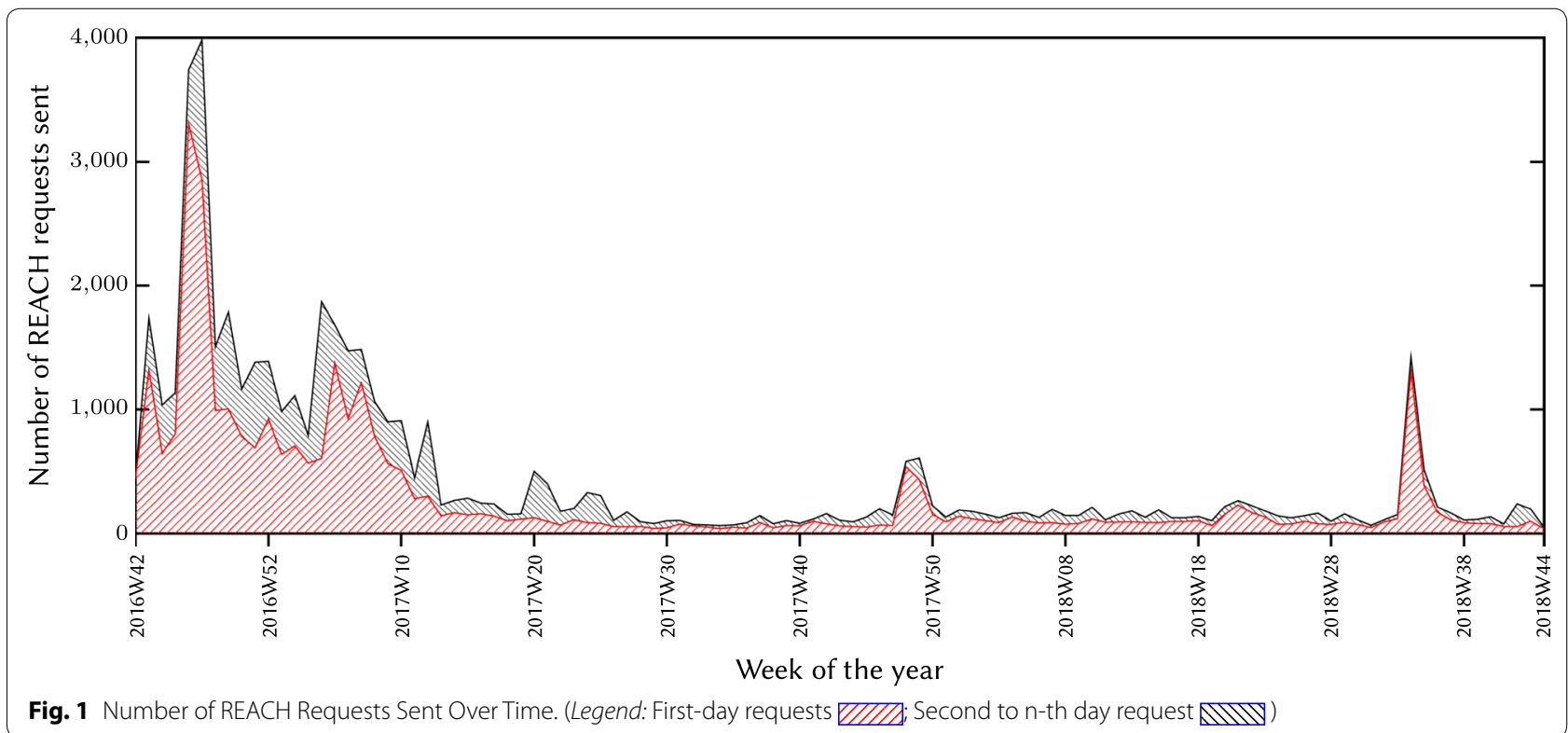

a response by a firm to a user or an email by the administrator to a user (mostly final notification after a firm's response). For each entry, our data set includes a timestamp and IDs for the SVHC request, user, article and firm as well as a variable for the state of the request (waiting, overdue, answered, unanswered, not applicable), the product category of the requested article (see Table 1) and a binary variable that indicates whether a product has been marked as containing SVHC above the threshold or not. The first and last entry in our data set are on 20th October 2016 and 31st October 2018.

We primarily use our data set to perform descriptive analysis. In addition, the panel structure of our data set allows us to draw statistical conclusions as to whether receiving information on requested articles encourages further use of the application. We model

$$
\begin{aligned}
\text { Requests }_{i, t}= & a+\beta_{0} \text { Entries }_{i, t}+\beta_{1} \text { Entries }_{i, t-1} \\
& +\cdots+\lambda_{t}+\alpha_{i}+\epsilon_{i, t},
\end{aligned}
$$

where Requests $s_{i, t}$ is the number of requests sent by user $i$ at week $t$. Entries ${ }_{i, t}$ is the number of entries into the database at week $t$ (of which the user was notified by BUND) for articles requested by user $i$ in previous weeks. ${ }^{26}$ Correspondingly, Entries $i, t-1$ capture the effect of entries of the preceding week $t-1$ on requests sent in week $t . \lambda_{t}$ are binary (dummy) variables for time periods that capture time fixed effects. $\alpha_{i}$ are dummy variables for users that

\footnotetext{
${ }^{26}$ Because requests may lead to entries within a week, such entries need to be excluded to prevent reverse causality.
}

capture user fixed effects. $\epsilon_{i, t}$ is the error term. For each user, time $t=1$ represents the week in which she sent the first request. For each week, the number of requests and entries are counted.

\section{Results}

Requests by consumers and answers by firms

The database has recorded 49,000 requests sent by users until 31st October 2018, i.e. 66 per day on average. As Fig. 1 shows, there is considerable variation over time. For example, from 14th to 20th November 2016, users have sent 3984 requests, i.e. $8 \%$ of overall requests. Table 1 shows the number of requests per product category. The information on the categories is provided by the users

Table 1 Requests by product category

\begin{tabular}{lcc}
\hline Product category & Number of requests & \% of requests \\
\hline Construction material & 11 & 0.02 \\
Furniture & 75 & 0.15 \\
Electronics & 460 & 0.94 \\
Household goods & 566 & 1.16 \\
Toiletries & 3218 & 6.58 \\
Clothing & 223 & 0.46 \\
Cosmetics & 14116 & 28.86 \\
Food & 8420 & 17.21 \\
Toys & 1311 & 2.68 \\
Sporting goods & 43 & 0.09 \\
Other & 9914 & 20.26 \\
No category & 10571 & 21.61 \\
\hline
\end{tabular}




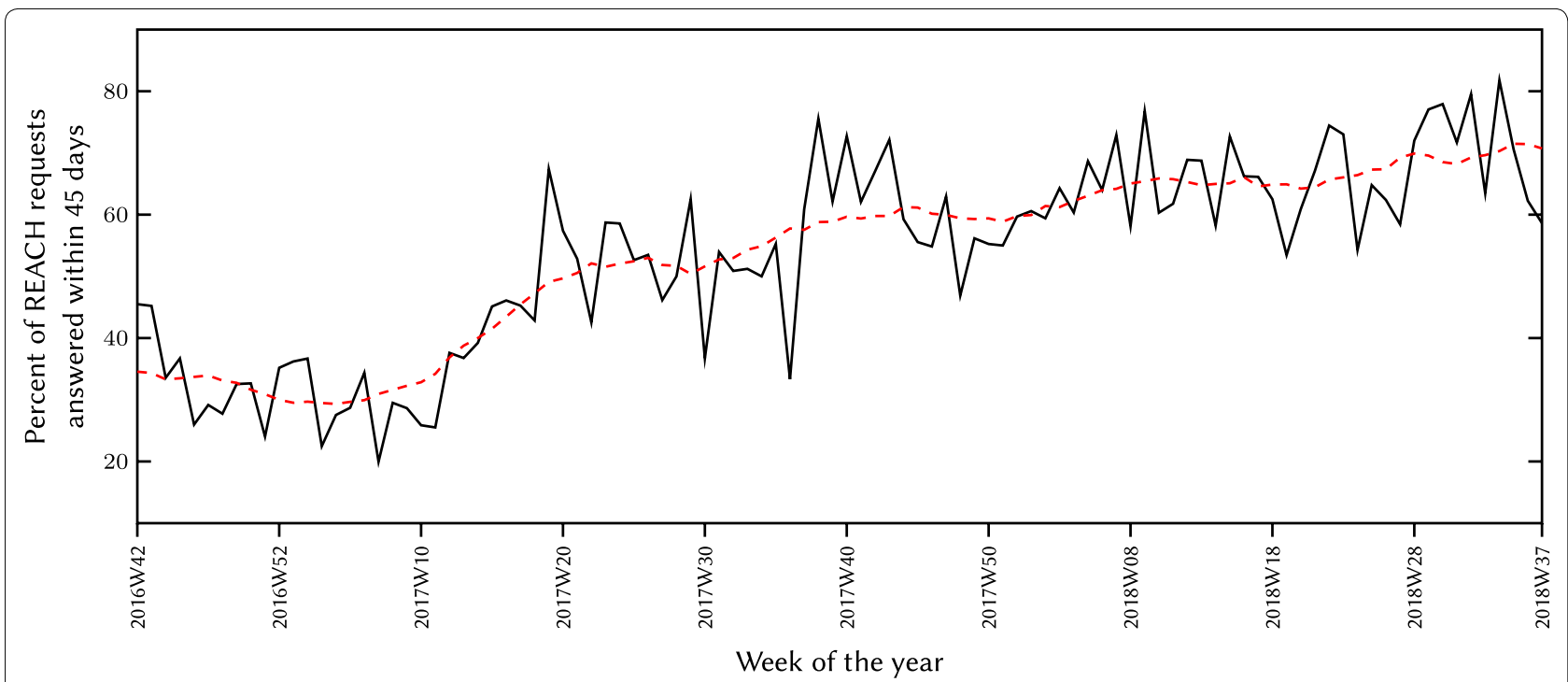

Fig. 2 Percentage of REACH Requests Answered Within 45 Days Over Time. (Legend: __ Current observation; - - - Moving average with a maximum of seven lagged and forward terms each, current observation is included)

and should therefore be interpreted with caution. As can be seen from Table 1, not all requested articles have been categorised at the time of data retrieval. Moreover, the fact that ToxFox was originally only applicable for EDCs in cosmetics could explain the comparatively high proportion of requests targeting this product category. ${ }^{27}$

Users can send requests for a specific article as long as its SVHC status is unknown to the application. Hence, multiple requests per article are possible. Users sent about 6 thousand requests as "reminders" to firms who did not answer within the legal time frame of 45 days. Furthermore, taking account of multiple requests across individuals, 15 thousand requests were sent for articles already requested by another user. Hence, requests for about 28 thousand different articles were sent. The requests were addressed to about 3,200 different firms, with an average of 15 requests per firm. Compared to the low number of requests indicated by industry representatives in the 2012 review of REACH [12, 32], and reported in media, ${ }^{28}$ the application has contributed to a considerable increase in the number of Art. 33(2) requests by consumers.

Firms replied to two-thirds of the requests. Because Art. 33(2) does not oblige firms to reply to requests if an article contains SVHCs under the legal threshold,

\footnotetext{
${ }^{27}$ The packing of cosmetic products falls under the REACH term of articles, while the right-to-know does not apply to the cosmetics as such.

${ }^{28}$ For instance, two major Danish retailers, Coop and Bestseller, reported that until the beginning of 2014 they received eight consumer requests (Coop) or "around one a month" (Bestseller) [13].
}

an absent reply does not necessarily imply non-compliance. As discussed in the 'Background' section, the low response rate may also be explained by (1) a lack of incentives for non-EU GTIN owners, (2) alleged legal uncertainties for firms regarding Art. 33 as well as (3) a lack of compliance with the provision. Over time, the percentage of firms that answered within the legal time frame of 45 days has risen. About $33 \%, 42 \%$ and $70 \%$ of requests sent in 2016, 2017 and 2018 were answered within 45 days, respectively (see Fig. 2 for the percentage of requests answered in a timely manner per week of the year). Increased awareness of the REACH obligation together with an increased acceptance of the application's approach may explain this development.

\section{Database building}

For only $20 \%$ of requests, information on the SVHC status of the article is eventually added to the database. There are several explanations for the low ratio of data records to requests: First, the app itself is not able to detect whether a scanned article falls under Art. 33(2). Indeed, $57 \%$ of requests were sent for products not covered by Art. 33(2). To reduce the number of "not applicable" requests, BUND updated the application in March 2017 and introduced an additional step before users can send a request. In this step, users need to specify the product's category. Only if the user selects a category which is covered by Art. 33(2), a request is sent. Second, the BUND does not interpret the absence of a firm answer as meaning that an article does not contain SVHCs above the legal limit. Such a conservative 
Table 2 Frequency of users per number of requests sent

\begin{tabular}{lcc}
\hline Number of requests & Number of users & \% of users \\
\hline 1 & 12421 & 60.17 \\
2 & 3921 & 18.99 \\
3 & 1565 & 7.58 \\
4 & 883 & 4.28 \\
5 & 481 & 2.33 \\
6 & 331 & 1.60 \\
7 & 206 & 1.00 \\
8 & 174 & 0.84 \\
9 & 119 & 0.58 \\
$\geq 10$ & 542 & 2.63 \\
\hline
\end{tabular}

approach seems reasonable given the lack of compliance by firms discussed in the previous chapter. Third, even if firms provide answers to applicable requests, they may lack relevant information (e.g. clear reference to a specific article or to a SVHC) and can thus not be transferred to the database. One of BUND's central tasks is to assess whether responses by firms fulfil the information requirements of Art. 33(2) and can thus be transferred to the database.

Although BUND has only accepted 9.4 thousand answers, the BUND database contains SVHC-information for about 150,000 articles. This is because a few firms have used the supplier front end to provide data proactively. None of the articles for which firms provided information pro-actively apparently contain SVHCs triggering the right-to-know. At the time of writing, there are 189 articles with SVHCs in the database, i.e. about 2 percent of accepted requests. This implies that many firms also answer to requests, even if they are not obliged by Art. 33(2). However, since ECHA only places "relevant" [33] SVHCs on the list, i.e. mostly substances that are presumably used by industry in the production of articles, it is at least questionable whether the information provided by firms is correct; not least considering the experiences made by Art. 33(2) compliance projects by national REACH law enforcement (as discussed in Quantity and quality of suppliers' answers).

\section{Frequency of use by individual users}

Overall 20,634 users have sent requests. About $60 \%$ of these users have only sent a single request; $19 \%$ have sent two requests. Relatively few users have sent ten or more requests (542; see Table 2). However, even users who have sent multiple requests, may not use the application on a regular basis. For example, a user who has sent 10 requests may have done so in a single day. Indeed, $71 \%$ of users have sent all their requests in a single day and first-day requests
Table 3 Estimates of the effect of receiving information on articles on subsequent request behaviour

\begin{tabular}{llll}
\hline Independent variables & \multicolumn{2}{l}{ Models } & \\
\cline { 2 - 4 } & $\mathbf{( 1 )}$ & $\mathbf{( 2 )}$ & $\mathbf{( 3 )}$ \\
\hline Entries $_{t}$ & $0.083^{* * *}$ & $0.096^{* * *}$ & $0.113^{* * *}$ \\
& $(0.003)$ & $(0.002)$ & $(0.002)$ \\
Entries $_{t-1}$ & - & $0.030^{* * *}$ & $0.032^{* * *}$ \\
& - & $(0.002)$ & $(0.001)$ \\
Entries $_{t-2}$ & - & - & $0.015^{* * *}$ \\
& - & - & $(0.001)$ \\
Week dummies $_{\text {User dummies }}$ & Yes & Yes & Yes \\
Constant & Yes & Yes & Yes \\
$R^{2}$ adjusted & Yes & Yes & Yes \\
F-statistic & 0.422 & 0.052 & 0.059 \\
Number of observations & 5198.955 & 95.249 & 96.164 \\
Number of groups & 587788 & 580306 & 572824 \\
& 7482 & 7482 & 7482
\end{tabular}

${ }^{*} p<0.1,{ }^{* *} p<0.05,{ }^{* * *} p<0.01$. Models are estimated using ordinary least squares. Unit of observation is a user. Dependent variable: Number of requests sent per week. Standard errors in parentheses

account for almost two-thirds of overall requests (see Figure 1 for the number of first-day requests over time).

Without further information on user behaviour and motivation, it is difficult to draw clear conclusions about why most users do not send requests on a regular basis. The BUND dataset allows only a limited analysis in this respect. One potential reason for the high user attrition is that for only $20 \%$ of requests information on the SVHC status of the article is eventually added to the database. Not receiving information may discourage further use of the application and vice versa.

Table 3 shows the results of ordinary least squares estimations for different specifications of Eq. (1). In column (1) only the number of entries of the "current" week is included as the main explanatory variable. In columns (2) and (3), "lagged" values of the entry variable are added. As can be seen from Table 3, receiving information for previous requests has a positive and statistically significant effect on the number of requests sent thereafter. As expected, the effect size is largest for information received in the same week. There is also a positive and significant effect for information that was received one or two weeks ago. Hence, the effect size diminishes over time. ${ }^{29}$

\footnotetext{
${ }^{29}$ From column (1) to (2), the variation of the data that is explained by the model decreases from $42 \%$ to $5 \%$. This is due to the inclusion of the lagged variable, for which data on the first week is missing. As mentioned above, most interaction with the application happens in the first week of use. The first week, therefore, has a lot of explanatory power as captured by the dummy variables for weeks included in the model.
} 


\section{Conclusion and recommendations}

Public disclosure of information is considered to be the "third wave" in toxic substance control policies [4]. It corrects for informational asymmetries between firms and the public and can create market-based incentives for firms to reduce their use of problematic substances. Moreover, public disclosure is subject to international law and policies.

Public access to information is also an important objective of $\mathrm{REACH}$ and the regulation gives consumers a right-to-know about SVHCs in articles. As the right-toknow provides the public with firm and article specific information, it has the potential to create market-based incentives for firms to reduce SVHCs. In the words of the European Commission, the right-to-know was included so "[c] onsumers can play an active role [...] by taking an interest in the safety of the articles they buy" ${ }^{30}$. However, the provision's operationalisation, most notably the article suppliers' response window of 45 days, does not assist consumers to make immediate informed decisions-at the point of sale in particular. Accordingly, several years after the information right entered into force, only a limited number of consumers have sent requests. At the same time, the European Commission states that companies "struggle" to respond to (the few) consumer requests received [34]. This lack in compliance with information obligations has also been observed for the registration programme of $\mathrm{REACH}[21,22]$. If firms have to fear stricter regulation or bad reputation, their incentives to truthfully self-report information are inherently perverted [35]. Apparently, the existing level of enforcement under REACH does not counter-balance these incentives sufficiently $[15,36]$. In fact, industry organisations are lobbying to weaken or even abolish Art. $33 \mathrm{REACH}$ [37]. Hence, for both suppliers and consumers, gaps in knowledge and comprehension apparently endure when it comes to chemicals in articles-a situation described as early as 1997 as "toxic ignorance" [38].

In an attempt to provide consumers and the public with information on SVHCs in articles more easily, European NGOs have developed smartphone applications that allow users to send requests and that store supplier responses in a database. Thereby, the applications make information about SVHCs in articles public and immediately available. Focusing on the smartphone application by the German NGO BUND, initial experiences indicate huge potentials. However, some challenges remain, causing the tool to perform below its alleged possibilities. First, only few firms pro-actively provide SVHC information about their articles to the database. This is

\footnotetext{
${ }^{30}$ http://ec.europa.eu/environment/chemicals/reach/right_en.htm.
}

somewhat surprising as firms that do not use SVHCs in their articles in relevant quantities have an incentive to voluntarily disclose this information to consumers-a process called "unraveling" in the disclosure literature [2]. The application thus far mainly depends on consumers to send requests to build up the database. Second, the data on users' interaction with ToxFox shows a high attrition over time. As shown in our analysis, this can in part be explained by users not receiving information on their requested articles. Overall, for only one-fifth of the requests, information was eventually added to the database. Hence, certain weaknesses in the design of this provision and its implementation should be considered. We therefore recommend the following options that address issues on three different levels: (1) governance (including enforcement and implementation), (2) smartphone applications for Art. 33(2) REACH, and (3) open research questions.

\section{Governance}

(1) In the first years of implementing $\mathrm{REACH}$, there have been legal uncertainties as to the reference point of the $0.1 \mathrm{wt} \%$ threshold stipulated by Art. 33 $\mathrm{REACH}$. For this reason, apparently, article suppliers were granted a "period of grace" by national enforcement agencies, whose overall market surveillance has not been very strict. However, the CJEU's judgement clarifying the "once an article always an article" interpretation is four years old as of September 2020. Hence, it is just and reasonable for enforcement to start making sure that firms comply with their information obligations regarding SVHCs. This is particularly important as market-based incentives can only advance the intended policy objective if the disclosed information is correct. Accordingly, the substances in articles enforcement pilot project report recommends to perform a proper enforcement project scaling up the pilot experiences [23].

(2) Companies are struggling with right-to-know requests because they have not ensured a steady flow of SVHC information in their supply chains, and are thus not in compliance with Art. 33(1) REACH. However, suppliers of articles are responsible for establishing structures that allow the necessary transfer of information. According to ECHA, companies who run systems ensuring traceability of supplied raw materials and article compositions have less difficulty in complying with these obligations [26]. The International Material Data System (IMDS), for example, allows the automotive industry to share information on the full com- 
position of articles used in vehicles. ${ }^{31}$ Such systems go well beyond chemical declaration requirements but make recycling quotas manageable and lay the foundation for sustainable production and consumption [39]. The European Commission should thus support companies to set up reliable communication systems [40]. To that end, related political commitments in the 2020 Circular Economy Action Plan [41] certainly show a way forward. The Commission should also take into account the Chemicals in Products Programme of the United Nations Environment Programme [42] as well as the "Proactive Alliance" ${ }^{\prime 2}$ initiated in 2018, as communication systems must allow for supply chain communication based on full material declaration [43]. Traceability of substances in articles is a precondition not only for compliance with Art. 33, but also for substance substitution.

(3) The Commission should use the review process to improve Art. 33(2) REACH, in accordance with the normative objective of $\mathrm{REACH}$ that "EU citizens should have access to information about chemicals to which they may be exposed, in order to allow them to make informed decisions about their use of chemicals" (Recital 117 REACH). The Comission should also be mindful of the more recent testimonies of political will in the European Green Deal [14] "[t]o ensure a toxic-free environment" and that "[c]onsumer policy will help to empower consumers to make informed choices and play an active role in the ecological transition". Notably, to overcome uncertainties related to the consumer right-toknow, an answer to the consumer should be obligatory also in cases, where an article does not contain SVHCs above $0.1 \mathrm{wt} \%$. As shown in our analysis, not getting an answer to a request discourages consumers from further using their right-to-know. Moreover, to increase the provision's practicability, the time limit for the reply should be reduced to a more reasonable period, with the aim of an immediate electronic reply. Other potential revisions of Art. 33(2) concern the depth of the information to be provided (see also recommendations for future research) and data protection of consumers. In its current form, a consumer is forced to disclose her name and e-mail or postal address.

(4) Using implementing legislation according to Art. $132 \mathrm{REACH}$, the Commission should also increase legal certainty in the implementation of
Art. 33(1) REACH by stipulating the duty to organise with regard to supply chain communication on SVHCs. ${ }^{33}$

(5) A sample letter for suppliers to answer consumer requests [18] distributed by ECHA e.g. as part of the Guidance on substances in articles, may help increase the quality of answers.

\section{Smartphone applications}

(1) Since few firms pro-actively provide SVHC information to the database, ToxFox depends on consumers to send requests. Therefore, gamification may be used to increase ToxFox users' intrinsic motivation to send requests. Gamification is the use of game-design elements and game principles, such as points, badges and leaderboards in non-game contexts $[45,46]$. Gamification has been successfully applied to increase user motivation in a number of different crowdsourcing and collaborative crowdscience projects $[47,48]$ and Q\&A Sites [49].

(2) Additionally, modifications on the consumer front end could strengthen the BUND's legal mandate to act on behalf of the users and thus increase suppliers' willingness to cooperate. One simple solution would be to add a tick box to the tool, allowing consumers to expressly declare that they confer a mandate to BUND, which is valid both for sending the request as well as for the receipt of the response. An alternative tool design, which only facilitates communication between consumer and supplier (as is the case with with the application(s) developed by the "LIFE AskREACH" project), rather than taking responsibility for this communication, would be another solution.

(3) Options as to how the quality of the data sources maintained by GS1 can be enhanced should be assessed. Thus far, the GTIN Management Standard does not require suppliers to assign a new GTIN when an article gets affected by a Candidate List update. These rules should be modified to the extent that a new GTIN must also be assigned when changes to the article formulation affect the information legally required on request by a consumer or other actor in the supply chain. Accordingly, variations of quality of the different production batches of the same articles must be taken into account. To be prepared for future right-to-know

\footnotetext{
${ }^{31}$ www.mdsystem.com.

32 www.proactive-alliance.info.
}

\footnotetext{
33 The authors develop a series of additional regulatory options in the research project "Advancing REACH" [44].
} 
requests, every batch should be assigned an individual GTIN as is already common practice for some companies.

(4) Because REACH can only be enforced inside the EEA, GTIN owners outside the EEA lack incentives to respond to Art. 33(2) requests. For such articles, ToxFox could ask users to indicate the retailer as supply chain actor situated in the EEA. Retailers are suppliers too, and thus obliged under Art. 33(2) REACH. At the same time, retailers can use their contractual relationships to obtain SVHC information as legal enforcement of Art. 33(1) REACH against non-EEA GTIN owners. The application(s) developed by the "LIFE AskREACH" project make use of this possibility.

\section{Research}

(1) The design of applications assessed in this study is particularly customised to interact with article bar codes. However, more and more purchases are made online, where the GTIN, if existent, is usually not visible to the consumer. Besides, some companies, big brands with their own retail stores in particular, have established their own proprietary bar code systems. Research should therefore assess alternative article identifier schemes, capable of integrating existing systems, thereby allowing for unequivocal identification of unique articles.

(2) More research that evaluates the impact of disclosure of information on SVHC and tools such as ToxFox, taking into account user awareness and motivation is needed. An important question relates to the type and depth of information provided to consumers. Ideally, the information would enable consumers to make a proper risk assessment. This requires information on both the toxicity of and the exposure to the chemical [15]. On the other hand, behavioural research from other areas like nutritional information shows that information that allows consumers to apply fast heuristics (like a traffic light rating system), outperforms more complex information when it comes to making quick decisions [50]. Which kind of information is best suited in the context of toxic chemicals is a promising avenue for future research. Initial evidence from survey research suggests that simple binary information signals (contains SVHCs above threshold or not) lead, as expected, to extreme behavioural intentions [51]. Depending on the results of future research, a revised version of Art. 33(2) may oblige firms to provide more complex information, thus allowing a more nuanced risk assessment. Another open research question regards consumer preferences for information retrieval and how smartphone tools compare to more traditional transparency instruments such as product labelling. The "LIFE AskREACH" project will contribute to the research questions raised.

\section{Abbreviations}

BUND: Bund für Umwelt und Naturschutz Deutschland; ECHA: European Chemicals Agency; CJEU: European Court of Justice; EEA: European Economic Area; GEPIR: Global Electronic Party Information Registry; GTIN: Global Trade Item Number; IMDS: International Material Data System; REACH: Registration, evaluation, authorisation and restriction of chemicals; SVHC(s): Substance(s) of very high concern.

\section{Acknowledgements}

We are grateful for the remarks by the reviewers helping us to improve the article.

\section{Authors' contributions}

$M B, M F$ and JS drafted and wrote the manuscript. MB, MF, JS and KB contributed to the draft and provided feedback to the manuscript. All authors read and approved the final manuscript.

\section{Funding}

This work has been supported by the German Federal Ministry for Education and Research as part of the research project KInChem (FKZ 01UT1419A-B). Open Access funding provided by Projekt DEAL.

\section{Availability of data and materials}

The data that support the findings of this study are available from BUND e.V. but restrictions apply to the availability of these data, which were used under license for the current study, and so are not publicly available.

\section{Ethics approval and consent to participate}

Not applicable.

\section{Consent for publication}

Not applicable.

\section{Competing interests}

The authors declare that they have no competing interests.

\section{Author details}

${ }^{1}$ Society for Institutional Analysis (sofia), Darmstadt University of Applied Sciences, Darmstadt, Germany. ${ }^{2}$ Chair of Economic Policy and SME Research, University of Göttingen, Platz der Göttinger Sieben 3, 37073 Göttingen, Germany.

Received: 19 May 2020 Accepted: 12 August 2020

Published online: 08 September 2020

\section{References}

1. UNECE (1998) Convention on access to information, public participation in decision-making and access to justice in environmental matters. Aarhus, Denmark: United Nations Economic Commission for Europe

2. Dranove D, Jin GZ (2010) Quality disclosure and certification: theory and practice. J Econ Lit 48:935-963

3. Mastromonaco R (2015) Do environmental right-to-know laws affect markets? Capitalization of information in the toxic release inventory. $J$ Environ Econ Manag 71:54-70 
4. Tietenberg T (1998) Disclosure strategies for pollution control. Environ Res Econ 11:587-602

5. Konar S, Cohen MA (1997) Information as regulation: the effect of community right to know laws on toxic emissions. J Environ Econ Manag 32:109-124

6. Bui LTM, Mayer CJ (2003) Regulation and capitalization of environmental amenities: evidence from the toxic release inventory in massachusetts. Rev Econ Stat 85:693-708

7. Grant D, Jones AW (2004) Do manufacturers pollute less under the regulation-through-information regime? Sociol Q 45:471-486

8. Weil D, Fung A, Graham M, Fagotto E (2006) The effectiveness of regulatory disclosure policies. J Policy Analy Manag 25:155-181

9. Fung A, O'Rourke D (2000) Reinventing environmental regulation from the Grassroots up: explaining and expanding the success of the toxics release inventory. Environ Manag 25:115-127

10. Weil D, Graham M, Fung A (2013) Targeting transparency. Science 340:1410-1411

11. Bae H, Wilcoxen P, Popp D (2010) Information disclosure policy: do state data processing efforts help more than the information disclosure itself? J Policy Anal Manag 29:163-182

12. CSES (2012) Interim Evaluation: Functioning of the European chemical market after the introduction of REACH. Kent, United Kingdom: Centre for Strategy and Evaluation Services. https://goo.gl/Rma37j Accessed 13 July 2018

13. Stringer $L$ (2015) Phone apps drive surge in SVHC requests: Consumer uptake growing of in-store tool. ChemicalWatch. Retrieved 13 July 2018. https://goo.gl/WvTqZ4

14. EC (2019) Communication from the Commission. The European Green Deal. COM (2019) 640 fin. Brussels, Belgium: European Commission. https ://bit.ly/3gnX0JF Accessed 02 August 2020

15. Coria J (2018) Policy monitor-the economics of toxic substance control and the reach directive. Rev Environ Econ Policy 12:342-358

16. Coria J, Autade A (2018) Analyzing the effects of the candidate list of substances of very high concern on chemical production in Sweden. Working paper. Department of Economics, University of Gothenburg, Gothenburg, Sweden

17. Zagel C, Niels A, Bodendorf F (2017) Using smartphones for information retrieval in omnichannel scenarios-assessing the effectiveness of technological triggers. In: Ahram TZ, Karwowski W (eds) Advances in The Human Side of Service Engineering. Springer, Cham, pp 151-159

18. Klaschka U (2017) Where are the SVHCs? Environ Sci Eur 29:24

19. Schenten J, Führ M (2016) Svhc in imported articles: reach authorisation requirement justified under wto rules. Environ Sci Eur 28:21

20. Scheidmann H (2017) Der ToxFox wildert: Der BUND promotet seine App Toxfox für Verbraucher-Anfragen nach SVHC in Erzeugnissen. Reach plus 4

21. ECHA (2016) Report on the Operation of REACH and CLP 2016. Helsinki, Finland: European Chemicals Agency. https://goo.gl/5W9E5W Accessed 13 July 2018

22. EC (2018) Commission staff working document accompanying the document communication from The commission to the European Parliament, the council and the European economic and social committee commission general report on the operation of reach and review of certain elements conclusions and actions Swd/2018/058 Final. Brussels, Belgium: European Commission. https://goo.gl/xxyLAz Accessed 13 July 2018

23. ECHA (2019) FORUM substances In Articles Pilot Project Report Harmonised Enforcement Pilot Project on Substances in Articles. Helsinki, Finland: European Chemicals Agency. Retrieved 09 März 2020. https:// doi.org/10.2823/846508

24. Scheidmann $\mathrm{H}$ (2017) Keine hilfe aus dem dilemma - zum neuen leitfaden für erzeugnisse und seinen aussagen zu den informationspflichten für komplexe erzeugnisse. Reach plus 7

25. Bergkamp L, Herbatschek N (2015) The "once an article, always an article" approach: Reflections on the advocate general's opinion on the concept of "articles" under reach. Eur J Risk Regul 6:155-164

26. ECHA (2017) Guidance on Requirements for Substances in Articles. European Chemicals Agency, Helsinki. https://doi.org/10.2823/470616

27. SHRG (2013) Jaarrapportage Handhaving REACH en EU-GHS, (2012) Samenwerkingsverband Handhaving REACH en EU-GHS.https://goo.gl/ B4CCGu Accessed 13 July 2018
28. KEMI (2012) Enforcement of the information duty in REACH - Inspection project 2011-2012. Bromma, Sweden: Swedish Chemicals Agency. https //goo.gl/gMp8La Accessed 13 July 2018

29. KEMI (2016) Strategy for enforcement of chemicals in articles. Bromma, Sweden: Swedish Chemicals Agency. https://goo.gl/p3ujUb Accessed 13 July 2018

30. Wursthorn S, Adebahr W (2013) Erfahrung beim vollzug der informationsverpflichtungen nach artikel 33 der reach-verordnung. Zeitschrift für Stoffrecht 10:245-252

31. Wursthorn S (2018) Enforcement of SVHC. Ministry of the Environment, Climate protection and Energy Sector Baden-Württemberg (Germany). https://goo.gl/6U9LAz Accessed 13 July 2018

32. RPA (2012) Assessment Of The Health And Environmental Benefits Of Reach. Final Report Part B - Assessment of Benefits. Loddon, England: Risk \& Policy Analysts Limited https://goo.gl/keHcCa Accessed 13 July 2018

33. ECHA (2013) SVHC Roadmap to 2020 Implementation Plan. ECHA-13R-11-EN, Helsinki, Finland: European Chemicals Agency. https://goo. gl/4HizXy Accessed 13 July 2018

34. EC (2018) Commission General Report on the operation of REACH and review of certain elements - Conclusions and Actions. Brussels, Belgium: European Commission https://goo.gl/BtYrtq Accessed 13 July 2018

35. Kaplow L, Shavell S (1994) Optimal law enforcement with self-reporting of behavior. J Polit Econ 102:583-606

36. Buxton $L$ (2018) Decade of REACH dossier evaluation reveals $70 \%$ noncompliance. Shrewsbury, UK: Chemical Watch. https://goo.gl/AuXjQ8 Accessed 21 Nov 2018

37. Buxton L (2016) Change "dead law" on SVHCs in articles, urges Ueapme. Shrewsbury, UK: ChemicalWatch. https://goo.gl/M5y2nX Accessed 13 July 2018

38. EDF (1997) Toxic Ignorance: The Continuing Absence of Basic Health Testing for Top-Selling Chemicals in the United States. New York, NY, USA: Environmental Defence Fund. https://goo.gl/hbrExf Accessed 13 July 2018

39. Führ M, Schenten J (2018) Sustainable production and consumption (spc). In: Krämer, L., Orlando, E. (eds.) Principles of Environmental Law. Elgar Encyclopedia of Environmental Law series, vol. 6. Edward Elgar Publishing Ltd,. Chap. 9

40. EC (2017) Scientific and technical support for collecting information on and reviewing available tools to track hazardous substances in articles with a view to improve the implementation and enforcement of Article 33 of REACH. Brussels: DG ENV (European Commission)

41. EC (2020) Communication from the Commission. A new Circular Economy Action Plan. For a cleaner and more competitive Europe. COM(2020) 98 fin. Brussels, Belgium: European Commission. https://bit.ly/319Pg7Z Accessed 02 August 2020

42. UNEP (2015) Guidance For Stakeholders On Exchanging Chemicals In Products Information Saicm/lccm.4/11. SAICM/ICCM.4/11, Geneva, Switzerland: United Nations Environment Programme. https://goo.gl/v2X2jP Accessed 13 July 2018

43. Stringer $L$ (2018) Cross-sector initiative sets full materials disclosure goal. ChemicalWatch. https://goo.gl/7WcWZw Accessed 13 July 2018

44. Führ M, Schenten J (2020) Advancing REACH: substances in Articles. UBA Texte, Umweltbundesamt, Dessau/Darmstadt. forthcoming

45. Deterding S, Sicart M, Nacke L, O'Hara K, Dixon D (2011) Gamification. using game-design elements in non-gaming contexts. In: $\mathrm{CHI}$ '11 Extended Abstracts on Human Factors in Computing Systems. CHI EA '11, pp. 2425-2428. ACM, New York, NY, USA

46. Huotari K, Hamari J (2012) Defining gamification: A service marketing perspective. In: Proceeding of the 16th International Academic MindTrek Conference. MindTrek ACM, New York'12, pp. 17-22.

47. Cooper S, Khatib F, Treuille A, Barbero J, Lee J, Beenen M, Leaver-Fay A, Baker D, Popović Z, Players F (2010) Predicting protein structures with a multiplayer online game. Nature 466:756-760

48. Morschheuser B, Hamari J, Koivisto J, Maedche A (2017) Gamified crowdsourcing: conceptualization, literature review, and future agenda. Int J Hum Comput Stud 106:26-43

49. Vasilescu B, Serebrenik A, Devanbu P, Filkov V (2014) How social q\&a sites are changing knowledge sharing in open source software communities. In: Proceedings of the 17th ACM Conference on Computer Supported Cooperative Work \& Social Computing - CSCW 14. ACM, New York 
50. Crosetto P, Muller L, Ruffieux B (2016) Helping consumers with a frontof-pack label: numbers or colors?: experimental comparison between guideline daily amount and traffic light in a diet-building exercise. J Econ Psychol 55:30-50

51. Hartmann S, Klaschka U (2018) Do consumers care about substances of very high concern in articles? Environ Sci Eur 30:29

\section{Publisher's Note}

Springer Nature remains neutral with regard to jurisdictional claims in published maps and institutional affiliations.
Submit your manuscript to a SpringerOpen ${ }^{\circ}$ journal and benefit from:

- Convenient online submission

- Rigorous peer review

- Open access: articles freely available online

- High visibility within the field

- Retaining the copyright to your article

Submit your next manuscript at $\boldsymbol{\nabla}$ springeropen.com 